\title{
El cuento de las pensiones. Miren Etxezarreta y José Iglesias, Icaria, 2019
}

\section{Melania Ferreira1}

\section{Lo imprescindible que sobre las pensiones debemos saber}

Los autores de este ensayo publicado por la editorial Icaria, ambos economistas y partícipes de movimientos sociales, muestran su compromiso social a través de una obra breve (apenas noventa páginas) y sencilla, pero contundente, que se aleja de la visión económica ortodoxa para tratar una cuestión vital que ha venido calificándose como conflictiva y ha hecho extender la alarma social en el Estado Español: las pensiones. Libre de tecnicismos intelectuales se expone de manera clara y concisa los argumentos y datos necesarios para desmontar el cuento de las pensiones -la "crisis de las pensiones"-, lo que señalan como una "construcción social deliberada". No solo desmontan los mitos que lo acompañan, sino que

${ }^{1}$ Grado de Sociología, Universidad de Barcelona 
apuntan directamente a las causas que los generan y las intenciones perversas que se encuentran tras ellos, además de proponer las diferentes medidas que podrían adaptarse para cambiar esta tendencia. Lo que hay de fondo es un análisis y una crítica bien fundamentados hacia el modelo neoliberal, pero también una llamada a la movilización.

Resultan cruciales la divulgación de análisis de fondo que puedan llegar a un amplio público y desmontar los cuentos que nos cuentan tal y como hacen los autores. De esta forma se da a conocer información vital sobre aspectos organizativos sumamente importantes de nuestra sociedad como son, en este caso, la distribución de la riqueza y la sostenibilidad de una vida digna para todos. Es un momento crucial no solo por lo que supone el estado actual de las pensiones en España, sino porque se están mercantilizando cada vez más aspectos básicos de sostenibilidad de la vida; con el objetivo de tener más conocimiento y herramientas para protegernos y combatirlo, sus autores construyen este ensayo.

Señalan los mitos -o lo que llaman falsas verdades, por ocultar aspectos que en conjunto resultan grandes mentiras- que han servido para argumentar la supuesta crisis de las pensiones.

El primero: aquel que afirma que el presupuesto de las pensiones debe estar equilibrado. Realmente esta es una afirmación ideológica puesto que los demás gastos si pueden generar déficit y son financiados por los impuestos generales.

El segundo mito proviene del discurso que emiten las grandes instituciones públicas internacionales: vivir más años supone un 
problema social. Aquí se olvida decir que muchos países tienen capacidad para generar riqueza y, en el caso de España, hay un gran número de personas dispuestas a trabajar que se encuentran en paro.

El tercer mito cae en la trampa de relacionar el número de trabajadores con la capacidad de financiamiento, cuando realmente lo que importa es la riqueza del país, y esta ha ido aumentando desde 1980 en una progresión media de un 2,2\% anual. La pregunta que formulan los autores sobre este mito es ¿A dónde va?, dicho de otra manera, ¿cuáles son las intenciones que hay detrás? Y formulan una pregunta relevante más: “ipor qué son solo ellos [los trabajadores] los que tienen que pagar las pensiones?"(página 29)

El cuarto mito es directamente una mentira: es la afirmación contundente de que no hay dinero. Los datos que presentan desmontan tal afirmación y señalan cuál es el problema real: la distribución de la renta. En España, entre el 54-52\% de la riqueza producida acaba en manos del capital mientras que los trabajadores son los que mayor esfuerzo fiscal realizan. Es verdad, no hay dinero para los que más contribuyen con su esfuerzo a producirlo.

El quinto mito que se señala es aquel que intenta convencernos de que las pensiones públicas en España son demasiado generosas, sin embargo, lo que realmente ocurre es que el salario de los pensionistas (y los salarios mínimos en general) son muy bajos: el 68,4\% de jubilados vive en el umbral de la pobreza (página 35). Por ello, apuntan los autores de este ensayo, la lucha de los salarios y de las pensiones constituyen el mismo problema que requiere reclamaciones unitarias de la ciudadanía y, sobre todo, requiere de

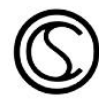


políticas de gobierno contrarias a cualquier planteamiento e imposición neoliberal.

Además, la supuesta deuda histórica es falsa puesto que antes de los Pactos de la Moncloa ésta presentaba superávit y se utilizaba para financiar otros gastos; no es hasta el 2009 que las cuentas de la Seguridad Social presentan déficit. La bajada de los ingresos y la subida del paro producen la reducción de las cotizaciones, pero la razón por la que las cuentas presentan déficit es debida a la inversión que hizo el Estado del casi el $100 \%$ del fondo de pensiones para comprar deuda pública (página 43), medida de la que la ciudadanía tiene apenas información.

Las reformas del sistema de pensiones en España se inician en 1985 y es en los Pactos de Toledo en 1995, como reacción al documento del Banco Mundial, cuando se realiza un planteamiento público del problema de las pensiones. Se separan las cuentas de las pensiones de las cuentas de la Seguridad Social y se crea el Fondo de Pensiones, este es el punto desde donde verdaderamente arranca un problema para el futuro de las pensiones.

Con la llegada de la crisis se desarrolla lo que los autores califican de neoliberalismo adulterado: hay un intento de privatizar más y las empresas, principalmente financieras, exigen más apoyo del Estado. Las reformas laborales del PSOE y del PP, en el 2012 y el 2013 respectivamente, van encaminadas a la disminución del gasto y el aumento de las pensiones privadas.

Tal y como remarcan los autores, es la búsqueda de nuevos nichos de mercado que permiten la expansión del capitalismo lo que

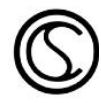


está detrás del objetivo y la estrategia neoliberal que se desarrolla desde la ruptura del keynesianismo en la década de los 70. Aquí es donde se inicia la necesidad de narración del cuento de las pensiones; es el relato que sirve para fomentar el modelo de pensiones privadas (un nicho de mercado sumamente rentable). Ya quedó demostrado en Chile que la introducción de políticas neoliberales impulsadas por la escuela de Chicago no produjo más que la verdadera crisis del sistema de pensiones. Lo que se está haciendo en España es atacar directamente a las pensiones públicas. Pero el discurso que oculta este proceso ha sido aceptado y ha calado en la opinión pública, se han servido para ello tanto de la publicidad de instituciones públicas como privadas, y también, por supuesto, se han servido de los principales medios de comunicación social (prensa, radio y televisión, los que más acceso tienen a la población) que han colaborado en extender este cuento que tan solo favorece a la política y la economía neoliberales.

Para que la ciudadanía acepte las medidas propuestas desde el Banco Mundial para establecer un sistema multipolar, donde las contribuciones de los trabajadores obligatorias sean gestionadas por entidades privadas, se les debe convencer primero de que no habrá dinero para las pensiones. No solo tenemos un sindicalismo débil para parar todo este proceso, además los sindicatos mayoritarios, como UGT y CCOO, con su actuación están siendo cómplices de estas privatizaciones, por ejemplo, lo están siendo cuando forman empresas con entidades financieras y defienden unas pensiones que no asegurarán el bienestar de los mayores de ninguna manera. Lo cierto es que, aunque se ha conseguido hacer creíble el cuento,

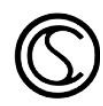


también existe una reacción social desde el 2016 que exige principalmente el incremento de las pensiones con relación al IPC. Sobre este punto, los autores creen que aún hay que ir más allá y, para ello, hay que analizar la cuestión de las políticas sociales (pensiones, paro, seguridad social, deuda...) en su conjunto y plantear y exigir el cambio de rumbo que es ya urgente y necesario.

La premisa que defienden los autores es clara: No es un problema de pensiones, es un problema de distribución de la renta. No es una crisis inevitable, sino que se pretende la privatización de los derechos sociales para el asegurar el beneficio de entes financieros privados. Ellos apuestan por la lucha hacia un sistema de pensiones públicas universal, desvinculado del empleo y del ejercicio del trabajo. 